\title{
Materials Challenges for the Next Century
}

\section{V.S. Arunachalam}

"After coating the wax figure over with clay the clever artisan should first dry and then heat the earthen mass to allow the wax to run out; it should now be filled with the desired metal and the cast image finished by breaking the burnt earthen mould and cleaning it with water."

Trans. in South Indian Bronzes (Lalit Kalā Akademi, India)

This is no ordinary explosion. The brilliant bursts of an aerial fireworks display, for example, quickly reach the natural limits of their expansion, arc to earth, and soon fade away-a fanciful memory. But the sustained explosion of microchip complexitydoubling year after year, decade after decade - has no convenient parallel or analogue in normal human experience. About the only eruption that comes close is the convulsive outburst that cosmologists consider to be responsible for the big-bang birth of the Universe, whose dim microwave afterglow two Bell Labs scientists discovered by accident in 1964, at almost the same time Moore was formulating his remarkable prediction.

M. Riordan and L. Hoddeson in Crystal Fire (1997)

The cliche "we live in a material world" seems so true. Even a cursory cataloguing of materials around us adds up to an impressive list. There are so many to choose from-and almost all of them new - that we now enjoy the luxury of choice, a privilege denied to our ancestors. More materials have come into being in this century than all past centuries combined. Michael Ashby, in one of his schematic diagrams, elegantly depicts the road traveled: from stones, flints, and pottery to tough engineering ceramics; from wood, skins, and fibers to polymers and plastics; from alluvial gold and copper to compound semiconductors. The list is truly grand.

History signposts periods of human achievement by the materials that made

'See M.F. Ashby, Phil. Trans. R. Soc. Lond. A 322 (1987) p. 393. them possible: neolithic, to remind us of artisans who molded clay to pottery; and chalcolithic, when metals were smelted and shaped. The Bronze Age. The Iron Age. And thus the list goes on. What materials should represent this century? The sheer number of possibilities and lack of a historical distance make this a difficult choice. The spectacular growth of materials science and technology in this century has made its impact on materials development. Scientific rigor and technological competence have transformed the profession to become more deliberate and purposeful. The hunter has become the tiller.

An option, converse to that adopted by historians, would be to identify the materials of this century through the engineering achievements they enabled. A summary of such an analysis should read more like an "Annual (or should we say, "Centennial"?) Report to Materials Community." This report, for instance, should identify steels by their role in making possible the truly impressive load-bearing structures of this century, and silicon through its enabling of the Information Technology (IT) Revolution. We should also enumerate the difficulties encountered in harnessing such materials, including the depletion of resources, pollution of the environment, and costs to the economy. We need this perspective to plan for the future.

As overtures for the next millennium begin to sound, we are tempted to speculate on materials that will persevere into the coming decades and beyond. In the midst of our discoveries, it was comforting to imagine that research and development determined the materials, the products, and even the market. But we now know that, more than ever, the market determines what the products will be. Good materials have floundered when there has been no market for them. The economist Joseph Schumpeter's ${ }^{\dagger}$ argument that societal demands drive development and even research, is seen to be true in practically every example of technology. But for the market's demands for faster air travel-freeing one from long, turbulent, and claustrophobic intercontinental journeys-and faster and more agile military fighters, there would have been no jet engines or high-temperature superalloys. It is therefore prudent to speculate on what our society's longings

†For further reading, see J. Schumpeter, Capitalism, Socialism and Democracy. (Harper, New York, 1942). are, and whether they are realizable at all with our current repertoire of knowledge and the materials required for the short term and for the decades beyond our current horizon. The need for new materials will emerge from such projections.

As overtures for the next millennium begin to sound, we are tempted to speculate on materials that will persevere into the coming decades and beyond.

Noted crystallographer and social scientist, J.D. Bernal, $\ddagger$ in one of his earliest essays, described three challenges: to develop a material world that includes travel into space to form colonies and create wealth, to be able to free oneself from diseases of the flesh, and to become more intelligent and rational. This list seems esoteric, but it provides a template. Perhaps we can transliterate the first longing as a challenge to develop efficient, pollutionfree transportation systems, from space vehicles to modern public transportation. These will need lighter, tougher, and more recyclable materials that are robust enough to withstand the demands of temperature and environment.

The second challenge would require new medicines and technologies that help overcome disabilities. This improved quality of life will demand materials that are affordable to provide sustainable and efficient energy systems in every sphere of human activity. The need for biomaterials will transcend what we know of them today. New materials benign to the human system are going to be needed to build replacement organs.

The third desire is more difficult to transliterate-as Bernal himself confessed-but can be rationalized as a need for a better and more equitable diffusion of knowledge among people. Long, thin threads of optical fibers, and tinier and tinier chips with faster and faster processing speeds, will be required to provide information to people when and where they want it.

ISee J.D. Bernal, The World, the Flesh, and the Devil; An Inquiry into the Future of the Three Enemies of the Rational Soul. (Indiana University Press, Bloomington [1929] 1969). 
In the coming months, MRS Bulletin will speculate on materials for the coming century through the products society would need and the services it would expect. The immediate future-the coming decade or even two-reveals itself in developments already visible. If a new semiconductor chip is to enter the market in the middle of the next decade, the equipment to manufacture it should be on design now. As yet, the technologies for building replacement livers or kidneys are not in place, but materials scientists are already busy working to develop the scaffolding materials needed to construct human replacement parts. Major surprises are unlikely to be seen immediately. Nevertheless, it is still important to catalog predicted developments to assess the tasks ahead for the decades to come. Beyond the immediate future must come the practical realization and further development of our present state of knowledge. Beyond this time horizon, it is difficult to predict. By achieving what we set to realize in the coming decades, we shall be transformed. Becoming different, we will desire something new, not on the basis of what we know today, but on what we will know then. Of course, it is possible that a new discovery will define an entirely new development trajectory, making all the extrapolations of our present knowledge irrelevant. To be deterred by such chance occurrences, however, is to abandon cataloguing the tasks ahead.

Governmental policies and societal concerns will also influence the development of technologies and materials. The Kyoto protocol, to cite an example, when ratified by all nations, will shape the energy technologies of the coming decades. Our concerns about the large stockpiles of plutonium compel us to develop options for tomorrow's nuclear fuels. Ethical issues may also be involved in consuming materials in limited supply or that pose envi-

If the Industrial Revolution
freed people from physically
demanding and mind-
numbing mechanical chores,
and fueled the blossoming of
materials science and
technology, the IT Revolution
promises even more.

ronmental hazards. The interdependence of technologies may also make predictions in a single area uncertain: There would have been no magnetic memories without computers for processing them. We minimize this unpredictability by focusing on market demands. Assuming that technologies for meeting such demands will emerge, we must search for the materials they require.

We begin our prediction on materials in the February issue of MRS Bulletin with a summary of what we have achieved in this century, both in our understanding and our practical realization. This will be followed in the coming months by a series of invited articles on materials that may enable us to address the societal challenges and technology needs for 2000 and beyond. We shall include in this series articles on materials that may fuel the IT Revolution. If the Industrial Revolution freed people from physically demanding and mind-numbing mechanical chores, and fueled the blossoming of materials science and technology, the IT Revolution promises even more. From informing and enlightening us with knowledge, IT plans to interconnect people and society as was never attempted before. The "Global Family" may finally become a reality, made possible through materials that readily respond to tiny atomic particles called electrons or the glimmer of light known as photonics. We shall speculate on these materials and those beyond: the ones that would replace these "almost by magic" materials. There is a danger that our speculations may turn out to be wrong-an occupational hazard when we attempt to prognosticate. But this should not prevent us from predicting and planning. The future, it is said, is a function of our own action. By predicting materials for tomorrow, we are opening a debate that could help set the agenda for materials research and development for decades to come. While we dare predict, we shall leave it to our successors at MRS Bulletin at the end of the next century to assess how well our guesses turn out! For us, this journey alone is heady enough.

FOR FURTHER READING: National Research Council, Materials Science and Engineering for the 1990s: Maintaining Competitiveness in the Age of Materials (National Academy Press, Washington, DC, 1989); National Research Council's Committee on the Survey of Materials Science and Technology, Materials and Man's Needs (National Academy Press, Washington, DC, 1975).

V.S. Arunachalam is a Distinguished Service Professor in the Department of Materials Science \& Engineering, Engineering $\mathcal{E}$ Public Policy, and The Robotics Institute of Carnegie Mellon University in Pittsburgh, Pennsylvania. His current research interests are in integrated materials design, issues on the development of infrastructure technologies, and lightwave communications. He is a former president and a Fellow of the Indian National Academy of Engineering and a Foreign Member of the Royal Academy of Engineering (United Kingdom). He has a PhD degree from the University of Wales and honorary doctorates from a number of universities.

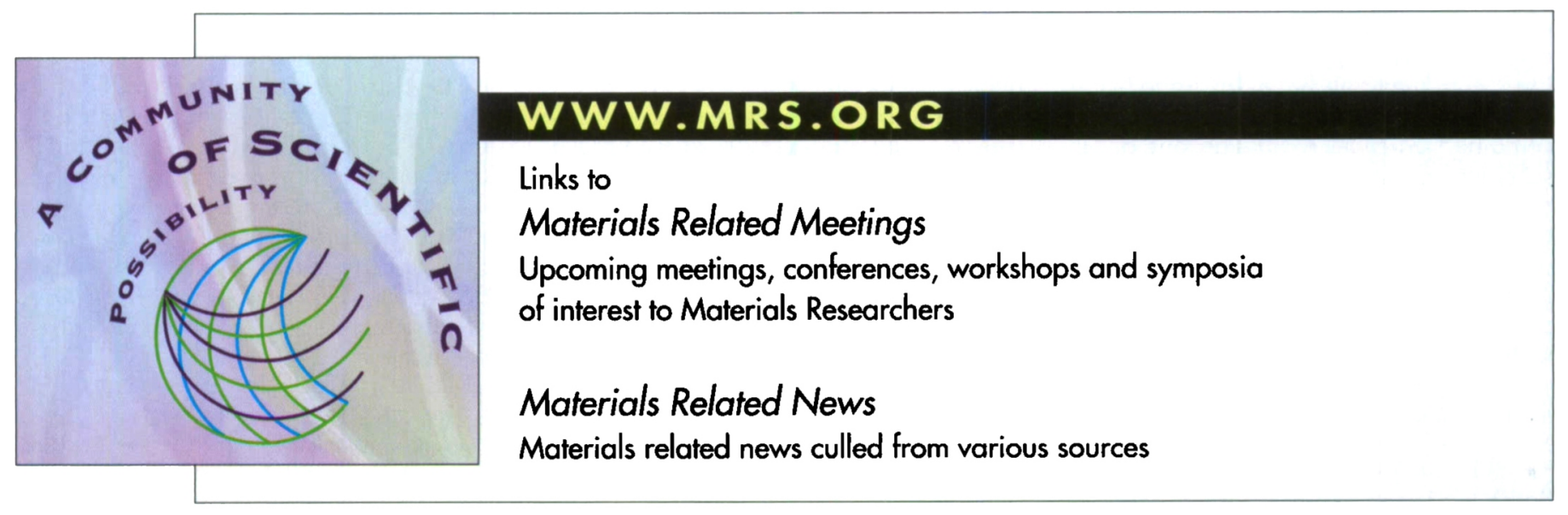

